\title{
DISTRIBUIÇÃO POTENCIAL DE OLIVEIRAS NO BRASIL E NO MUNDO ${ }^{1}$
}

\author{
MARCOS SILVEIRA WREGE ${ }^{2}$, ENILTON FICK COUTINHO ${ }^{3}$, \\ ANGÉLICA PRELA PANTANO ${ }^{4}$, ROGÉRIO OLIVEIRA JORGE 3
}

RESUMO-A demanda pelo azeite de oliva tem sido crescente no mundo, principalmente no Brasil, aumentando a necessidade de expansão da área de plantio. Contudo, nas regiões que são tradicionalmente produtoras, não existe mais espaço, havendo necessidade de procurar novas áreas para plantio no mundo. Neste trabalho, foram identificadas áreas marginais para plantio no Brasil, utilizando modelagem de nicho ecológico, baseando-se em pontos de ocorrência levantados nas regiões produtoras da Europa, Estados Unidos, Austrália e América Latina (Chile, Argentina e Uruguai). Foram usados 346 pontos georreferenciados de ocorrência e planos de informação com dados climáticos (média de temperatura mínima do ar, média de temperatura máxima do ar - em ${ }^{\circ} \mathrm{C}$ - e total de precipitação pluviométrica - em $\mathrm{mm}$ ) estacionais (primavera, verão, outono e inverno) do mundo, baixados do site do Worldclim. Os dados foram organizados e formatados em sistemas de informações geográficas, usando ArcGIS 10. Finalmente, foram elaborados mapas com a probabilidade de ocorrência de oliveiras no mundo. Foi feito também um mapa apenas da América do Sul, em que são apresentadas as zonas com maior potencial de ocorrência de oliveiras.

Termos para indexação: modelagem de nicho ecológico, oliveiras, azeite de oliva.

\section{POTENCIAL DISTRIBUTION OF OLIVE IN BRAZIL AND WORLDWIDE}

ABSTRACT - Demand for olive oil has been increasing worldwide, especially in Brazil, increasing the need for expansion of planting area. However, in regions that are traditional producers, there isn't more space, we need to seek new areas for planting in the world. In this study, we identified marginal areas for farming in Brazil, using ecological niche modeling, based on occurrence points raised in the producing regions of Europe, United States, Australia and Latin America (Chile, Argentina and Uruguay). It was used 346 georreferenced occurrence points and climatic data layers (mean minimum air temperature, mean maximum air temperature - in ${ }^{\circ} \mathrm{C}$ - and total rainfall - in $\mathrm{mm}$ ) seasonal (spring, summer, autumn and winter) of the world, downloaded from the site of Worldclim. The data were organized and formatted in geographic information systems (GIS), using ArcGIS 10. Finally, we made maps with probability of olive trees in the world. It was also made a map just of South America, with the most suitable areas for planting olive trees. Index terms: ecological niche modeling, olive oil, olive production in Brazil.

\footnotetext{
${ }^{1}$ (Trabalho 174-14). Recebido em: 16-05-2014. Aceito para publicação em: 30-09-2014.

${ }^{2}$ Engenheiro Agrônomo, Doutor, Pesquisador da Embrapa Florestas, Estrada da Ribeira, km 111, Colombo-PR E-mail: marcos.wrege@ embrapa.br

${ }^{3}$ Engenheiro Agrônomo, Doutor, Pesquisador da Embrapa Clima Temperado, BR 39, km 78, Pelotas-RS.

${ }^{4}$ Engenheiro Agrônomo, Doutor, Pesquisador do IAC, Av. Barão de Itapura, 1481, Campinas-SP.
} 


\section{INTRODUÇÃO}

Nos últimos anos, em função do aumento de demanda, vem crescendo a necessidade de expansão das áreas de plantio pelo mundo. Contudo, não existe mais área disponível nos países tradicionalmente produtores de oliva. Na busca por novas áreas, a tendência é de que a cultura venha a ocupar zonas marginais e, assim, surge a necessidade de desenvolver novas cultivares, próprias para essas novas zonas, adaptadas ao novo ambiente. O clima é o fator determinante na escolha dos locais mais indicados para o plantio, uma vez que influencia diretamente no florescimento, na polinização, na fixação (fruit set), na época de maturação dos frutos e na qualidade da azeitona de mesa e do azeite. Portanto, plantar no lugar certo é fundamental, não apenas para conseguir produzir, mas, acima de tudo, para atingir a qualidade necessária para a colocação do azeite de oliva no mercado nacional.

A oliveira (Olea europaea L.) é uma planta angiosperma dicotiledônea da família oleaceae, de porte arbóreo e de clima mediterrâneo. Graças à sua estrutura xerofítica, desenvolve-se bem, mesmo em ambientes com verões longos, quentes e secos, e com baixos índices pluviométricos. É cultivada no sul da Europa, nos países mediterrâneos, como Portugal, Espanha, França, Itália e Grécia. A cultura expandiuse para outros países, cujas características de clima são semelhantes às de países do sul da Europa, como Norte da África, América do Norte e América do Sul, além de alguns países da Ásia (ALBIN;VILAMIL, 2003). A origem não é bem definida, sendo atribuída à Síria ou à Líbia, onde já era cultivada havia mais de 10.000 a.C. A oliveira pode ter chegado primeiro à Grécia, em 700 a.C; a Marselha, em 600 a.C., e, finalmente, a Roma, em 500 a.C. (WREGE et al., 2009; SANTOS, 2002).

No século XVI, a colonização espanhola levou as oliveiras para as Américas. Inicialmente, no século XVIII, foi introduzida no México, no Peru, no Chile, na Argentina, nos Estados Unidos (Califórnia), na Jamaica e na Austrália. Mais recentemente, foi introduzida também no Japão, na África do Sul, no Uruguai e no Brasil (WREGE et al., 2009; COUTINHO et al., 2009; SANTOS, 2002). Atualmente, o cultivo está sendo intensificado, inclusive, na Espanha, na Itália, em Portugal, no Chile, na Austrália, nos Estados Unidos (Califórnia), na Argentina e no Uruguai. A divulgação das qualidades nutricionais, dietéticas e organolépticas do azeite extravirgem, principalmente dos monovarietais, com sabores e aromas incomparáveis, com baixa acidez, estimula seu consumo cru e como incremento em saladas (OLIVEIRA et al., 2002; ROMERO ; GUTIÉRREZ, 2002; ALBIN; VILLAMIL, 2003; WREGE et al., 2009; SANTOS, 2002).

$\mathrm{Na}$ safra de 2011 / 2012, os maiores produtores de azeite de oliva foram: Espanha (1.613 mil toneladas, representando 43\%), Itália (450 mil toneladas, 18\%), Grécia (295 mil toneladas, $13 \%)$, seguidos da Tunísia (6\%), Turquia (6\%), Síria (4\%), Marrocos (3\%); e de azeitona de mesa, foram: Espanha (27\%), Turquia (15\%), Egito (12\%), Síria (6\%), Marrocos (6\%), Argentina (5\%), Grécia (5\%), Estados Unidos (5\%) e Itália (4\%) (International Olive Oil Council, 2013; Conselho Oleícola Internacional, 2008). De outro lado, os maiores importadores foram: Estados Unidos (133 mil toneladas), Brasil (68 mil toneladas) e Itália (58 mil toneladas). Os maiores produtores de azeitona de mesa foram: Espanha (521 mil toneladas), Egito (500 mil toneladas) e Turquia (400 mil toneladas). Os maiores importadores de azeitona de mesa foram: Estados Unidos (133 mil toneladas), Brasil (100 mil toneladas) e Rússia (68 mil toneladas). Em 2012/2013, o Brasil encontra-se em terceiro lugar entre os países que mais importam azeite de oliva, com cerca de 73 mil toneladas de azeite (International Olive Oil Council, 2013), 30 mil toneladas a mais que em 2009 (OLIVEIRA et al., 2012), sendo o quinto país que mais consome azeite, mesmo não sendo produtor expressivo.

Devido à pequena área de plantio e produção insignificantes no Brasil, pelo fato de ter condições climáticas apenas marginais para o desenvolvimento desta cultura, o País importa estes produtos para atender à demanda interna. Em 2009, foi elaborado um zoneamento agroclimático para oliveiras no Rio Grande do Sul e um zoneamento edafoclimático, indicando as zonas com menores riscos climáticos para produção de oliveiras no Estado (WREGE et al., 2009; FILLIPINI ALBA et al., 2014). Atualmente, existem pequenas áreas plantadas no Rio Grande do Sul e em Minas Gerais.

No clima mediterrâneo, durante o inverno, ocorre acumulação de frio, a qual é considerada indispensável para que a oliveira saia da dormência e atinja, posteriormente, florescimento uniforme. A temperatura-base, abaixo da qual não ocorre crescimento, e a planta, portanto, entra em dormência, é de $12,5^{\circ} \mathrm{C}$ (TAPIA et al., 2003).

De acordo com experiências de plantio nos países do mediterrâneo, a temperatura adequada para que ocorra a frutificação efetiva normal, deve estar entre os $25^{\circ} \mathrm{C}$ e $35^{\circ} \mathrm{C}$. As plantas, contudo, são capazes de suportar altas temperaturas no verão próximas a $40^{\circ} \mathrm{C}$, sem que os ramos e folhas sofram 
queimaduras. Porém, a atividade fotossintética passa a ser inibida quando a temperatura ultrapassa os $35^{\circ} \mathrm{C}$ (COUTINHO et al., 2007). A oliveira é mais sensível ao frio que outras espécies frutíferas. Contudo, ocorre um aumento gradual de tolerância, provocada pelas baixas temperaturas outonais, responsáveis pelo estímulo da planta à dormência. Assim, a oliveira chega a resistir a temperaturas pouco inferiores a $0^{\circ} \mathrm{C}$. Pequenas lesões em brotos e ramos novos podem ocorrer, se a temperatura baixar, ficando entre $0^{\circ} \mathrm{C}$ e $-5^{\circ} \mathrm{C}$. Se a temperatura baixar ainda mais, para até $-10^{\circ} \mathrm{C}$, podem ocorrer danos definitivos nos brotos e ramos. Abaixo de $-10^{\circ} \mathrm{C}$, a planta, como um todo, pode sofrer danos irreversíveis e morrer (NAVARRO; PARRA, 2008).

A oliveira é cultivada normalmente em regiões semiáridas do mediterrâneo, caracterizadas por apresentarem elevadas temperaturas e baixo índice pluviométrico (250-550 mm anuais) nos meses secos (verão) (WREGE et al., 2009; FILLIPINI ALBA et al., 2014; COUTINHO et al., 2007). A oliveira é uma espécie com muitas características de plantas xerófitas, com folhas coriáceas, de cutícula espessa. Os estômatos situam-se na face inferior das folhas, diminuindo as perdas de água da planta por transpiração e permitindo que a atividade vegetativa se restabeleça imediatamente quando a planta sai de uma situação de estresse, causado por falta de água prolongada. A necessidade de água, em média, é de 650-800 mm por ano, com chuvas, preferencialmente, regulares (WREGE et al., 2009; FILLIPINI ALBA et al., 2014; COUTINHO et al., 2007; ALBIÑANA, 2002). Na primavera, quando ocorre o florescimento, as chuvas não devem ser muito frequentes, para que o grão de pólen não seja lavado do estigma, o que reduziria a frutificação efetiva. Nas fases de prématuração e maturação dos frutos (final do verão e outono), as chuvas não devem ser muito intensas, para que o fruto não fique excessivamente aguado, o que dificulta e encarece a extração do azeite, além de deixar a extração mais lenta. Isto pode, também, reduzir a estabilidade do óleo e favorecer a ocorrência de antracnose (Gloeosporium olivae) nos frutos, com alterações nas propriedades físicas e químicas do azeite (ALBA, 2004).

Na primavera, quando a temperatura está em ascensão e supera $15-17^{\circ} \mathrm{C}$, ocorre o desencadeamento do processo de florescimento, como resultado da saída da dormência. Existem etapas distintas desta fase - a de início, florescimento pleno, polinização e frutificação efetiva (conhecida, também, como fruit set). Nesta importante fase de desenvolvimento da planta, a temperatura diária deve ficar em torno de $20^{\circ} \mathrm{C}$, a fim de que todos os processos metabólicos ocorram normalmente. A umidade relativa do ar deve ficar entre $60-80 \%$. Caso contrário, a viabilidade do estigma pode ser comprometida, principalmente se a umidade ficar abaixo de 50\%. Nesta situação, o estigma pode durar menos de três dias, tempo insuficiente para formar o tubo polínico e, assim, formar e fixar o fruto. Por outro lado, se a umidade relativa for muito elevada, próxima de $100 \%$, ocorre a hidratação do grão de pólen, que aumenta de peso e não pode ser levado a uma longa distância pelo vento. Existe ainda a possibilidade de o grão de pólen ser destruído devido ao excesso de hidratação (TAPIA et al., 2003). O excesso de umidade não só prejudica a polinização, mas também favorece as doenças fúngicas, entre as quais as causadas por Spilocaea oleagina, Pseudocercospora cladosporioides, Gloeosporium olivae, entre outras (GUCCI, 2007). Por estas razões, a umidade relativa é uma variável de referência na escolha de local para estabelecimento das oliveiras (WREGE et al., 2009).

O objetivo do presente trabalho é, usando modelagem de nicho ecológico, fazer uma análise comparativa crítica, estudando as regiões onde as oliveiras são plantadas hoje e, assim, determinar as possibilidades de plantio em outras regiões marginais, com as maiores similaridades climáticas possíveis em relação à região de origem. $\mathrm{O}$ estudo serve para indicar novas regiões com potencial para o desenvolvimento de oliveiras, mas, também, locais onde podem ser organizados experimentos para testes de novas variedades adaptadas às regiões marginais e, além disso, produtoras de azeite de oliva de qualidade.

\section{MATERIAIS E MÉTODOS}

Foram usados dados climáticos do WorldClim, com cobertura em todo o mundo, permitindo, dessa forma, relacionar espacialmente os locais de ocorrência de oliveiras com dados climáticos. Foi necessário usar uma base de dados mundiais, pois os principais pontos de ocorrência de oliveiras ocorrem ao redor dos paralelos $30^{\circ} \mathrm{N}$ e $30^{\circ} \mathrm{S}$, fora do Brasil, e o objetivo deste trabalho foi definir os melhores locais para o desenvolvimento de oliveiras no Brasil. Foram usados dados de médias de temperaturas mínimas do ar estacionais (primavera, verão, outono e inverno), médias de temperaturas máximas do ar estacionais e médias dos totais de precipitação pluvial estacionais. Usando sistemas de informações geográficas (software ArcGIS 10), os dados foram transformados para o formato do Open Modeler (formato tipo texto, com extensão ASC), programa 
usado para a modelagem de nicho ecológico.

Os mapas básicos usados foram elaborados pelo método da regressão linear múltipla, onde são relacionadas as variáveis climáticas com o modelo de superfície terrestre, os paralelos e os meridianos (WREGE et al., 2011; PINTO et al., 1972; ROBERTSON; RUSSELO, 1968). Essa técnica é muito empregada e recomendada para o mapeamento das temperaturas do ar.

A modelagem de nicho ecológico, usada para determinar a distribuição potencial de oliveiras no Brasil e no mundo, foi feita empregando-se diversos algoritmos, que são: Bioclim, Climate Space Model, Envelope Score, Environmental Distance, Maximum Entropy e Niche Mosaic. Cada simulação foi feita com as variáveis climáticas, isoladamente, utilizando os índices pluviométricos e as médias de temperaturas mínimas e médias de temperaturas máximas do ar. Cada variável foi analisada isoladamente e, posteriormente, as probabilidades foram juntadas em sistemas de informações geográficas, formando um mapa final. Cada variável foi analisada isoladamente para verificar a contribuição individual de cada uma e, assim, ajudar na escolha das variáveis a serem usadas na elaboração de um mapa final. Pela mesma razão, idêntico procedimento foi adotado para escolher o melhor algoritmo que determinasse a distribuição potencial da oliveira.

Foi elaborada uma planilha com dados de latitude e de longitude de cada região no mundo onde existe o cultivo tradicional de oliveiras, totalizando 346 pontos, ilustrados nas Figuras 1 a 5, que foram considerados pontos de ocorrência para efeito de modelagem de nicho. Os dados foram formatados para uso no Open Modeler (formato tipo texto, com extensão txt).

O software gerou arquivos com a probabilidade de ocorrência de oliveiras em formato de texto, com extensão asc.

O mapeamento da probabilidade de ocorrência de oliveiras foi feito em sistemas de informações geográficas (SIG), utilizando o software ArcGIS. Foram usados os arquivos gerados pelo Open Modeler, no formato de texto asc, os quais foram convertidos para formato do ArcGIS (formato raster). Foram somados os mapas com probabilidade de ocorrência da oliveira, gerados isoladamente para cada variável climática, usando os algoritmos Bioclim, Climate Space Model, Envelope Score, Environmental Distance, Maximum Entropy e Niche Mosaic. A classificação foi feita usando o limite de corte de 0,5, padrão do software Open Modeler. Finalmente, obteve-se o mapa final com a indicação das regiões com potencial de ocorrência de oliveiras no mundo, baseada nos índices pluviométricos e nas temperaturas do ar, as duas variáveis climáticas de maior peso na definição dos limites das zonas de ocorrência de oliveira, por ser uma espécie xerofítica e que necessita de horas de frio para uniformidade de florescimento e de frutificação.

\section{RESULTADOS E DISCUSSÃO}

O cultivo da oliveira no mundo:

O cultivo de oliveiras, no mundo, concentrase ao redor dos paralelos $30^{\circ} \mathrm{N}$ e $30^{\circ} \mathrm{S}$ (Figuras 1 a 6), regiões onde se encontram as zonas áridas ou semiáridas, de baixo índice pluviométrico e baixa umidade relativa do ar, em função das movimentações de massas de ar que ocorrem no globo terrestre. São zonas de alta pressão atmosférica, opostamente ao que ocorre na zona do Equador, zona de baixa pressão atmosférica e que concentra alto volume de chuvas. Tanto no paralelo $30^{\circ} \mathrm{N}$ quanto no $30^{\circ} \mathrm{S}$ existem similaridades climáticas. Além da aridez, também são zonas em que, no inverno, ocorrem temperaturas baixas, o que torna possível o acúmulo de horas de frio, responsável pela entrada em dormência da oliveira. Essas duas condições são fundamentais para o cultivo de oliveiras, considerando as cultivares existentes atualmente no mercado. Se, por meio do melhoramento genético, surgirem novas cultivares que não precisem de frio acumulado para a frutificação, ou que não tenham problemas de inviabilidade do pólen, em situação de umidade relativa do ar elevada, a geografia da olivicultura no mundo pode ser alterada.

Além da proximidade com o paralelo $30^{\circ} \mathrm{S}$, na América do Sul, verifica-se que as atuais zonas de plantio se concentram bem no interior do continente, onde os índices pluviométricos são menores, devido ao efeito de continentalidade. São zonas semiáridas e também são caracterizadas pela presença de frio, contabilizado pelo total de horas de frio acumulado. $\mathrm{O}$ frio é importante para dar uma pausa no crescimento da planta e, com isso, estimular a formação de compostos bioquímicos e proporcionar a concentração de hormônios que favorecem a brotação das gemas vegetativas e floríferas de modo mais uniforme no ciclo produtivo seguinte, refletindo positivamente na qualidade e no tamanho dos frutos (ALMEIDA; ANTUNES, 2012).

No Brasil, dificilmente são encontradas as duas condições simultaneamente em um mesmo lugar. Geralmente, as zonas que têm frio são zonas serranas, onde a umidade relativa do ar é mais elevada, e os índices pluviométricos são também mais elevados. As zonas com menor índice de 
pluviosidade situam-se, por outro lado, em locais quentes, sem acúmulo de frio, como é o caso do semiárido brasileiro.

O cultivo da oliveira no Brasil:

Na Figura 1, são apresentadas as regiões do Brasil com potencial de cultivo de oliveira. Mesmo nas regiões com potencial, existem riscos climáticos, devendo-se evitar as zonas com microclimas desfavoráveis, principalmente as baixadas com elevada umidade relativa, com formação de nevoeiro pela manhã ou à noite, assim como os topos de morros com ventos fortes.

A análise individualizada das variáveis climáticas na modelagem de nicho permitiu a observação de um padrão na distribuição potencial de oliveiras para os diversos algoritmos usados para cada variável climática, independentemente, permitindo analisar qual a variável que realmente limita o desenvolvimento da cultura no Brasil.

Em relação ao regime de chuvas, a melhor região para cultivo de oliveiras no Brasil seria o semiárido nordestino, onde o total de chuva acumulada em um ano é em torno de $600 \mathrm{~mm}$, parecido com o que ocorre no clima mediterrâneo da Europa (Figura 3), onde a oliveira é cultivada há centenas de anos, e com os demais climas no mundo, em que a espécie é cultivada há décadas. Pelas características xerofíticas da oliveira, seria a região ideal para seu cultivo no Brasil, se tivesse horas de frio acumuladas durante o inverno. Quanto à temperatura do ar, as melhores regiões encontramse no Sul do Brasil, principalmente nas zonas serranas do Rio Grande do Sul e de Santa Catarina, onde existem horas de frio acumuladas no inverno, necessárias à entrada em dormência para a oliveira. Contudo, a umidade relativa do ar é elevada durante a fase de florescimento, o que inviabiliza o grão de pólen e dificulta a frutificação.

A tarefa mais difícil é encontrar as zonas que apresentem o maior frio acumulado e também baixa umidade relativa do ar na fase de florescimento da oliveira. Isso é encontrado na fronteira oeste do Rio Grande do Sul que, embora tenha as condições mais propícias ao desenvolvimento da espécie no Brasil, ainda assim não tem as condições ideais. Por essa razão, é uma região marginal, mas que pode ser usada para cultivo da oliveira, com certo cuidado. Deve-se dar preferência aos microclimas de menor umidade relativa, com terrenos de face de exposição norte e com pouco vento. O sucesso da olivicultura depende da escolha da melhor cultivar indicada para cada região, isto é, de uma cultivar que sobreviva e produza em quantidade em uma região, conforme as características do clima e dos solos, e, ao mesmo tempo, tenha uma produção de azeitonas com qualidade comercial satisfatória, de acordo com as exigências de padrão internacional e que tenha produção de azeite de oliva de alta qualidade, de acordo com o padrão europeu (WREGE et al., 2009; FILLIPINI ALBA et al., 2014).

No momento, o desenvolvimento da olivicultura no Brasil, zona marginal para expansão da fronteira agrícola da cultura, basicamente, depende da definição das cultivares mais adequadas para cada região. $\mathrm{O}$ desempenho das cultivares no Brasil depende da capacidade em se desenvolver em ambientes com menos frio e, ao mesmo tempo, de ser capaz de frutificar com maior umidade relativa do ar na fase do florescimento, considerando-se, ainda, que o azeite de oliva a ser produzido deve manter o padrão de qualidade europeu, ou, no caso dos frutos, devem ter padrão internacional (WREGE et al., 2009; COUTINHO et al., 2009; FILLIPINI ALBA et al., 2014).

No passado, houve tentativas de plantio de oliveiras na zona litorânea do Rio Grande do Sul, no município de Rio Grande, que não tiveram êxito, justamente por estarem em uma zona com alta umidade relativa do ar e altos índices de pluviosidade, sem uma estação seca definida, embora a região tenha horas de frio acumuladas suficientes para o desenvolvimento da olivicultura.

Algumas pesquisas estão sendo feitas com experimentação a campo. Com os resultados destas pesquisas, poderá haver a indicação de cultivares mais adaptadas para cada região, conforme as características climáticas e as necessidades das cultivares testadas. O resultado da modelagem feita neste trabalho é um indicativo, baseado nas necessidades da oliveira, sem considerar detalhamento ao nível de cultivares, representando um estudo preliminar, com indicação da cultura como um todo. Indica quais são as regiões com o clima mais parecido ao da região de origem da oliveira, isto é, aquelas com maior potencial climático para o desenvolvimento da espécie no Brasil. As Figuras 1 a 6 apresentam as condições favoráveis na América Latina, inclusive no Brasil, além das condições favoráveis de plantio na Europa, África, Estados Unidos, México e Austrália, e são apresentadas para efeito de comparação com o clima do Brasil. Como pode ser observado, basicamente, não existem restrições para cultivo em uma grande área do Brasil, se considerarmos as temperaturas máximas e mínimas do ar das estações, principalmente nas regiões Sul e Sudeste. Por outro lado, quanto ao regime de chuvas, as restrições são maiores, e existem maiores 
diferenças em relação ao clima mediterrâneo, que é mais seco que o do Brasil, de modo geral, exceto na região Nordeste do Brasil, onde prevalece o clima semiárido, cujas características são mais próximas às do mediterrâneo. Desse modo, as regiões que agregam as melhores condições climáticas para o desenvolvimento de oliveiras, considerando-se as temperaturas, são as regiões Sul e Sudeste nas zonas de altitude. Considerando-se o regime de chuvas, a melhor região para cultivo de oliveiras é a Nordeste, no semiárido. Existem outros países da América Latina que agregam as duas características ao mesmo tempo, em um mesmo lugar (Chile, Argentina e, de certa maneira, Uruguai e Peru - neste último caso, em zonas de altitude). No Brasil, existe uma pequena faixa na fronteira com o Uruguai e Argentina (Fronteira Oeste), como já é apresentada no zoneamento agroclimático de oliveiras para o Rio Grande do Sul (WREGE et al., 2009) e no zoneamento edafoclimático da olivicultura para o Rio Grande do Sul (FILLIPINI ALBA et al., 2014), e uma faixa muito pequena no semiárido (Bahia). Existem manchas, também, no noroeste e no nordeste do Paraná e sudoeste de São Paulo (divisa com o Paraná), conforme ilustra a Figura 1. As melhores regiões para plantio são aquelas de coloração cinza (têm precipitação pluvial favorável), de hachuras com linhas diagonais (temperaturas mínimas favoráveis) e pontos (temperaturas máximas favoráveis), de acordo com as legendas das figuras.

Ainda assim, as novas zonas indicadas para a expansão da fronteira de produção da oliva são zonas marginais e, portanto, têm necessidade de acompanhamento das cultivares que têm melhor desempenho nestas novas áreas, observando, também, a qualidade da azeitona e do azeite de oliva produzido. A qualidade tem uma estrita relação com a cultivar usada e com o ambiente (WREGE et al., 2009; FILLIPINI ALBA et al., 2014).

Quanto ao processo de modelagem usado neste trabalho, os avanços recentes permitem modelar a distribuição das espécies baseados em atributos ambientais que podem ser correlacionados às necessidades do nicho das espécies. Os modelos podem predizer com sucesso locais com alta probabilidade de ocorrência de uma espécie em uma ampla variedade de ecossistemas (PETERSON, 2001; RAXWORTHY et al., 2003; LUOTO et al., 2005). Os modelos de distribuição de espécies descrevem o nicho fundamental da espécie, podendo ocorrer alguns tipos de erros, entre os quais erros de sobreprevisão, prevendo zonas além daquelas nas quais a espécie tem condições de sobrevivência (zonas onde a espécie tem condições ambientais para se desenvolver, mas onde não é verificada sua ocorrência). A modelagem considera somente as condições ambientais, desprezando as interações interespecíficas, como competição, por exemplo, e fatores históricos, tal como barreiras geográficas, entre outros (zonas desérticas, oceanos, cordilheiras, etc.) (CHESSON, 2000; CHAVE et al., 2002; COSTA et al., 2008). Dessa forma, uma espécie pode não ocorrer em uma região, porque nunca teve oportunidade, devido à existência de barreiras naturais, que separam a zona onde ocorre da zona onde tem potencial (BROWN et al., 1996; PATTERSON, 1999). Assim, uma espécie é apta a ocupar todo o espaço geográfico potencial, mas a presença de outras espécies e fatores históricos, frequentemente, podem reduzir esse espaço (HUTCHINSON, 1957; CHASE; LEIBOLD, 2003; ARAÚJO; GUISAN, 2006).

Enfim, este trabalho é importante para orientar pesquisadores na busca de novas regiões para o plantio da oliveira, servindo para testar novas variedades, em novas regiões, orientando onde são as melhores zonas para fazer novos experimentos com testes de cultivares, verificando qual a melhor cultivar comercial para cada região, estimulando a viabilização da produção sustentável de azeitonas e de azeite de oliva para o mercado interno e que, dessa forma, o Brasil possa reduzir suas importações, com a melhoria de renda e geração de empregos no campo. Espera-se, também, que este trabalho sirva para orientar trabalhos de melhoramento genético, indicando locais para implantação de experimentos e teste de cultivares adaptadas às zonas marginais. 


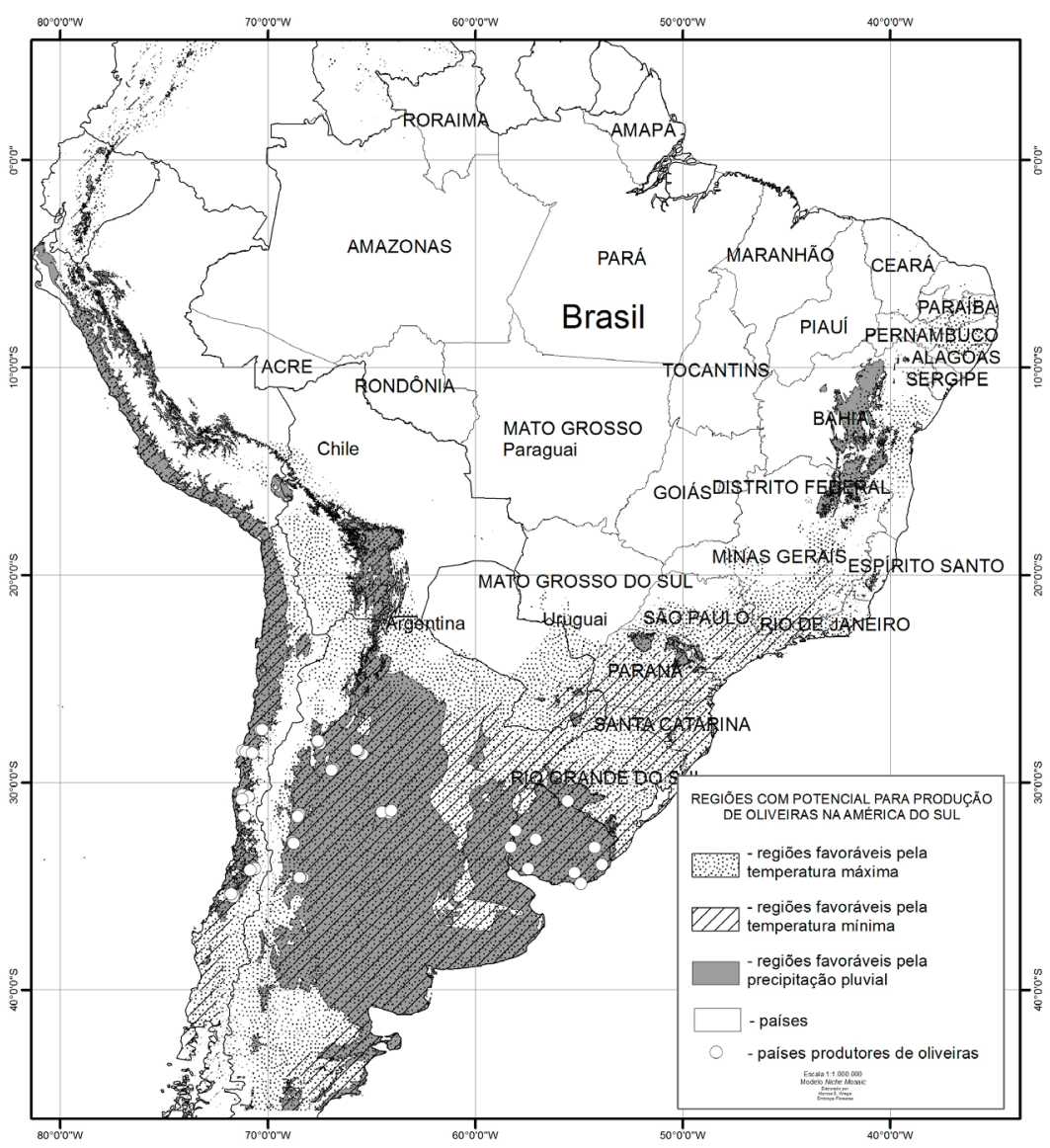

FIGURA 1-Delimitação de zonas com potencial para plantios de oliveiras na América do Sul.

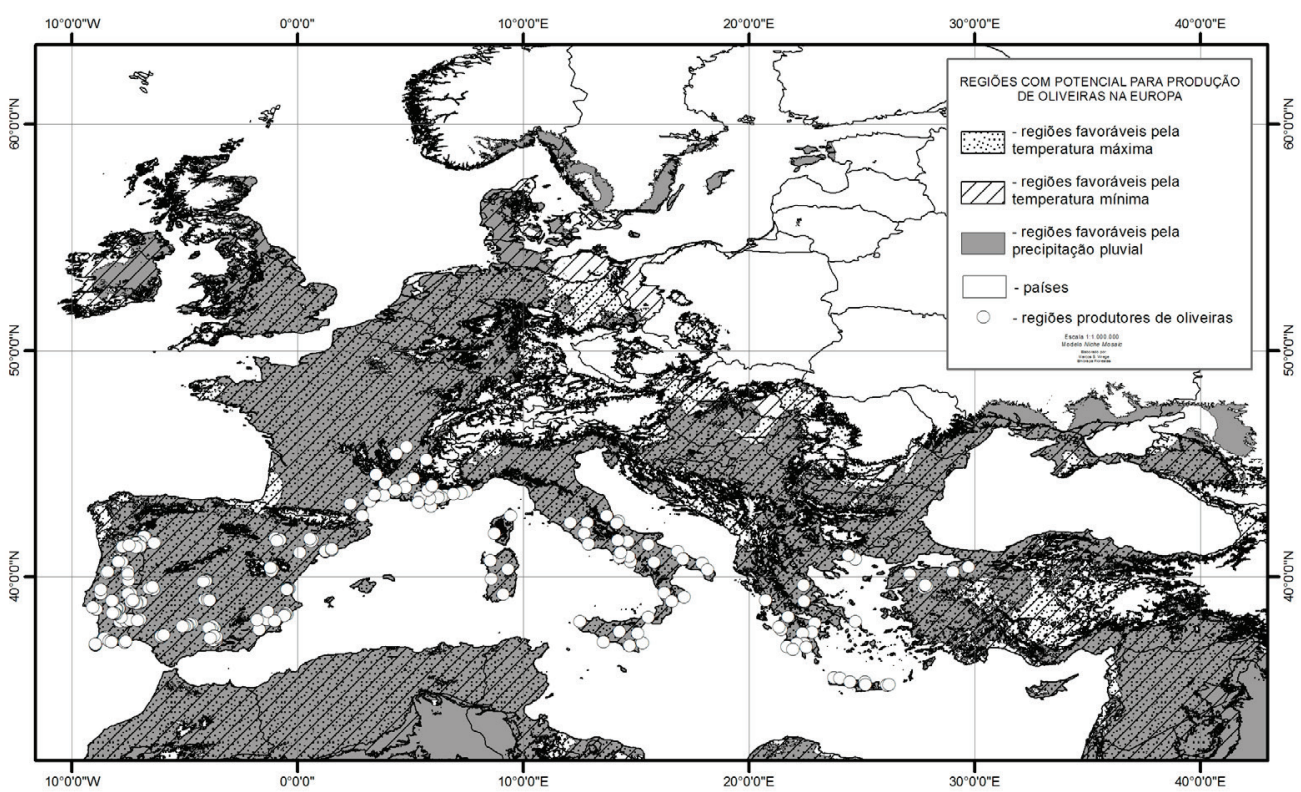

FIGURA 2- Delimitação de zonas com potencial para plantios de oliveiras na Europa. 


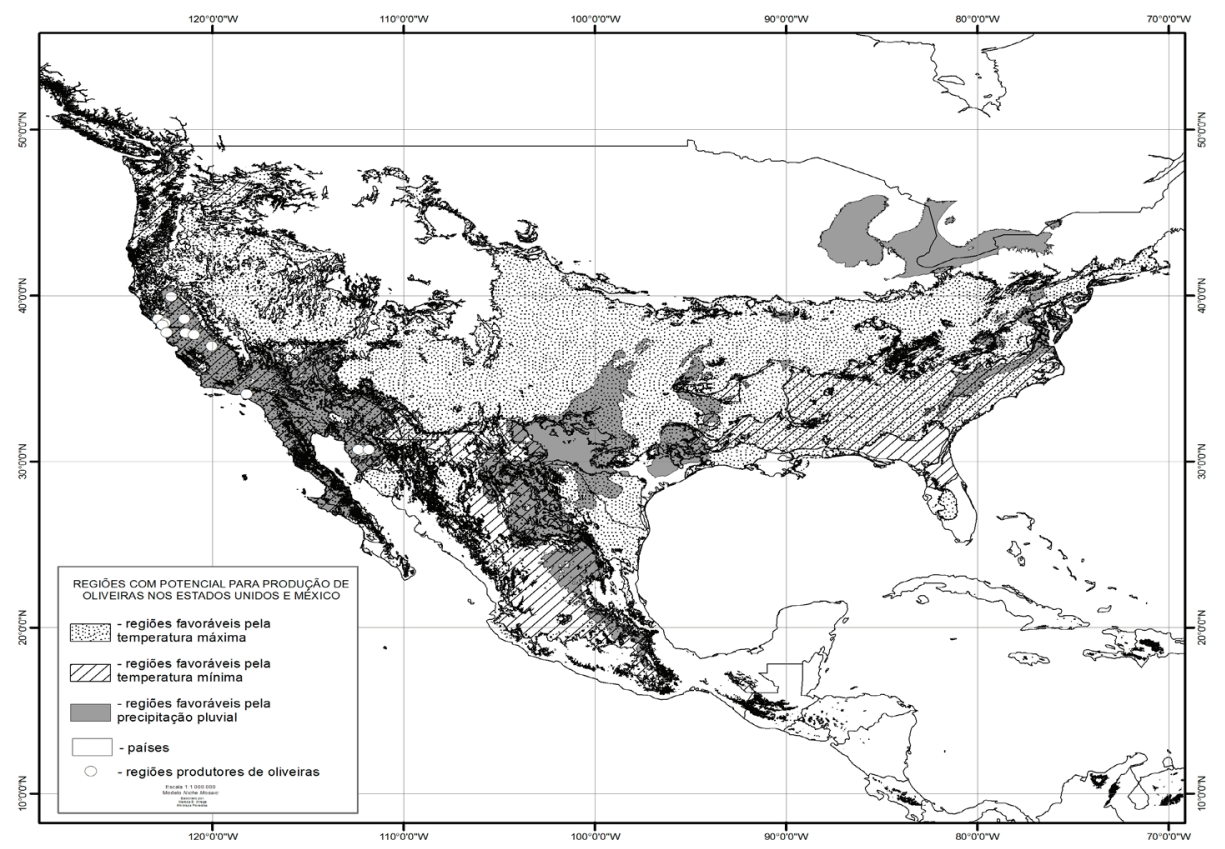

FIGURA 3- Delimitação de zonas com potencial para plantios de oliveiras na América do Norte.

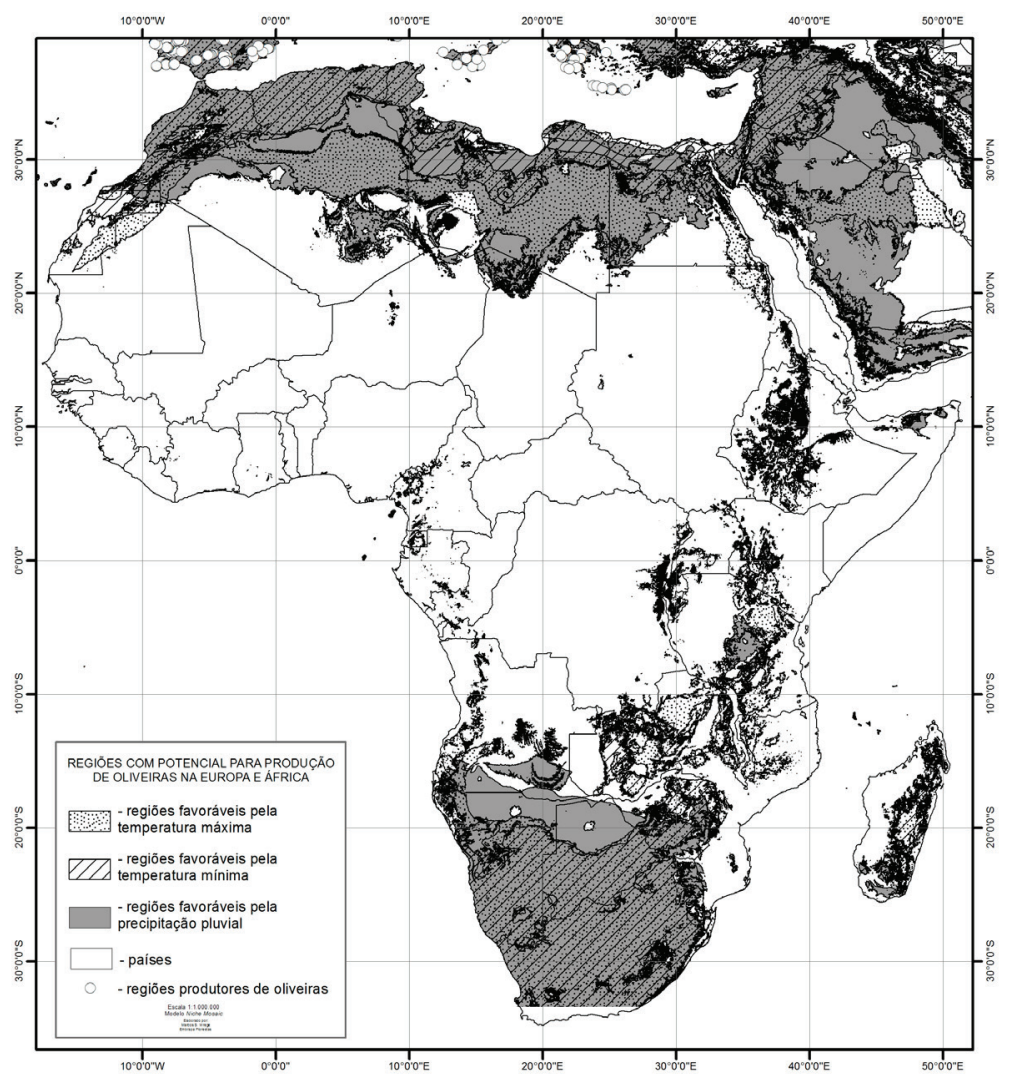

FIGURA 4-Delimitação de zonas com potencial para plantios de oliveiras na África. 


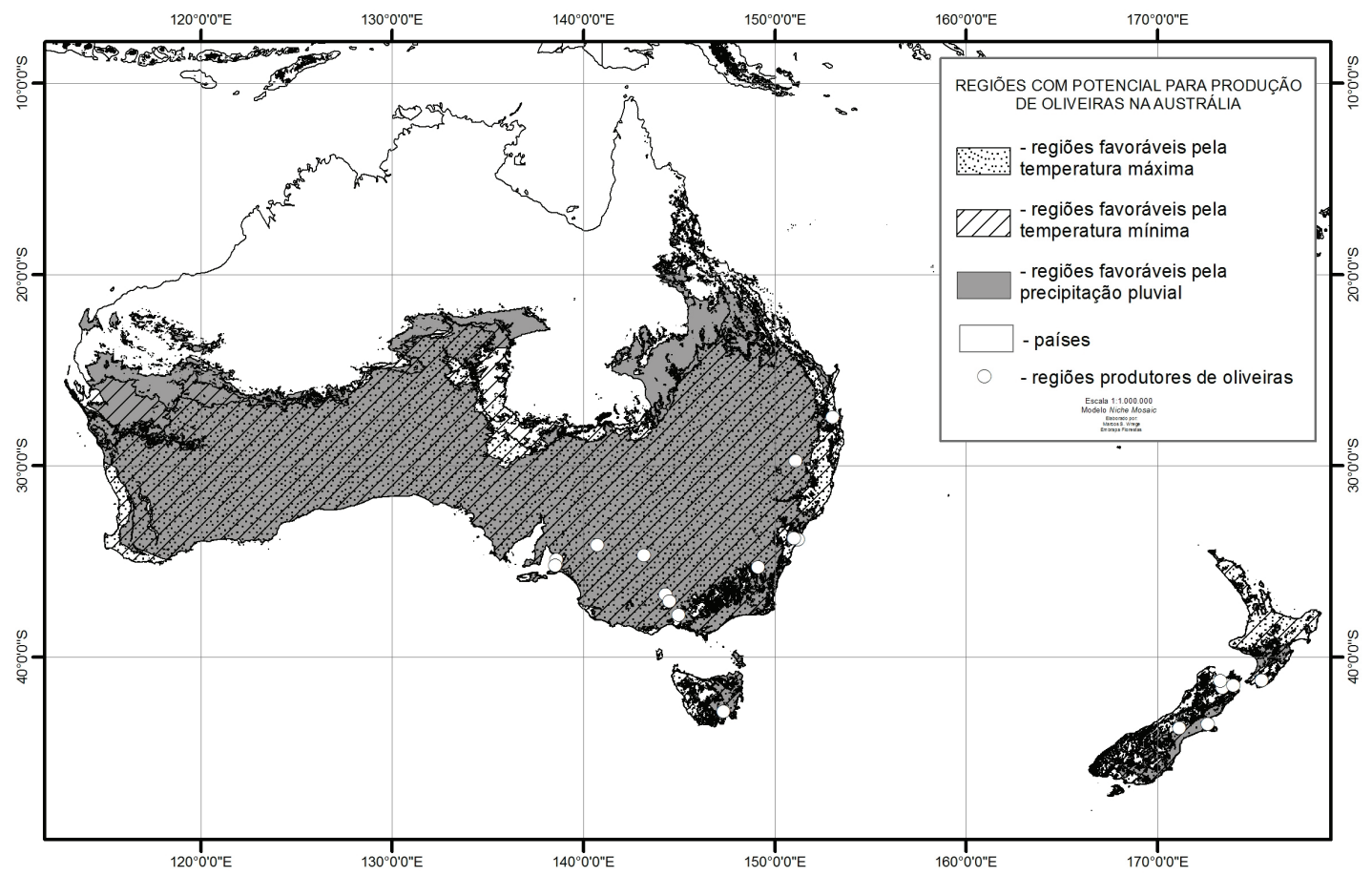

FIGURA 5- Delimitação de zonas com potencial para plantios de oliveiras na Austrália.

\section{CONCLUSÕES}

Existem poucas regiões, no Brasil, que agreguem as características climáticas necessárias para o desenvolvimento de cultivares de valor comercial de oliveiras, que são zonas com baixo índice pluviométrico, baixa umidade relativa do ar e acúmulo de horas de frio.

Embora não existam, como regra geral, condições favoráveis ao desenvolvimento da olivicultura no Brasil, algumas zonas são apontadas como mais favoráveis no semiárido, em zonas de altitude, onde existe um acúmulo mínimo de horas de frio, e na fronteira oeste do Rio Grande do Sul, onde existe frio e sazonalidade na distribuição de chuvas, favorecendo a atividade da olivicultura, desde que sejam escolhidas as cultivares corretas.

\section{REFERÊNCIAS}

ALBA, J. Elaboración del aceite de oliva virgen. In: BARRANCO, D.; FERNANDEZ-ESCOBAR, R. El cultivo del olivo. $6^{\text {th }}$ ed. Madri: Mundi-Prensa, 2004. p. 615-655.

ALBIN A.; VILlamil J. Aceite de oliva: tradicional sabor mediterráneo, rejuvenecido en tierras Uruguayas. Montevideo: Editora de Vecho, 2003. p. 25-28.

ALBIÑANA, L. I. Guía completa del cultivo del olivo. Barcelona: Editorial de Vecchi, 2002. 126 p.

ALMEIDA, I.R.; ANTUNES, L.E.C. Necessidades climáticas e influência do clima sobre adaptação, produção e qualidade. In: ANTUNES, L.E.C.; HOFFMANN, A. Pequenas frutas: o produtor pergunta, a Embrapa responde. Brasília: Embrapa, 2012. 194 p. 
ARAÚJO, M.B.; GUISAN, A. Five (or so) challenges for species distribution modelling. Journal of Biogeography, Oxford, v.33, p.1677-1688, 2006.

BROWN, J.H.; STEVENS, G.C.; KAUFMAN, D.M. The geographic range: size, shape, boundaries, and internal structure. Annual Review of Ecology and Sistematics, Palo Alto, v.27, p.597-623, 1996.

CHASE, J.M.; LEIBOLD, M.A. Ecological niches: linking classical and contemporary approaches. Chicago: University of Chicago Press, 2003.

CHAVE, J.; MULLER LANDAU, H.C.; LEVIN, S.A. Comparing classical community models: theoretical consequences for patterns of diversity. The American Naturalist, Salem, v.159, p.1-23, 2002 .

CHESSON, P. Mechanism of maintenance of species diversity. Annual Review of Ecology and Systematics, Palo Alto, v.31, p.343-358, 2000.

CONSELHO OLEÍCOLA INTERNACIONAL. Economia. Disponível em: <http://www. internationaloliveoil.org/web/aataliano/corp/ AreasActivitie/economics/AreasActivitie.html>. Acesso em: 31 set. 2008.

COSTA, G.C.; WOLFE, C.; SHEPARD, D.B.; CALDWELL, J.P.; VITT, L.J. Detecting the influence of climatic variables on species distributions: a test using GIS niche-based models along a steep longitudinal environmental gradient. Journal of Biogeography, Oxford, v.35, p.637-646, 2008.

COUTINHO, E.F.; WREGE, M.S.; REISSER JÚNIOR, C.; ALMEIDA, I.R. de; STEINMETZ, S. Cultivo de oliveira (Olea europaea L.): clima. Pelotas: Embrapa Clima Temperado, 2009 (Sistema de produção).

COUTINHO, E. F. A cultura da oliveira. Pelotas: Embrapa Clima Temperado, 2007. 143 p.

FILLIPINI ALBA, J.M.; FLORES, C.A.; WREGE, M.S.; COUTINHO, E.F.; JORGE, R.O. (Ed.). Zoneamento edafoclimático da olivicultura para o Rio Grande do Sul. Brasília: Embrapa, 2014. 80 p.
GUCCI, R. Ecofisiologia. In: FIORINO, P. Olea: tratatto di olivicoltura. Bologna: Edagricole, 2007. p. 77-111.

HUTCHINSON, G.E. Concluding remarks. Cold Spring Harbor Symposia on Quantitative Biology, New York, v.22, p.415-427, 1957.

INTERNATIONAL OLIVE OIL COUNCIL. Olive oil. Disponível em: $\leq$ http://www.internationaloliveoil. gov/>. Acesso em: 13 dez. 2013.

LUOTO, M.J.; HEIKKINEN, R.K.; SAARINEN, $\mathrm{K}$. Uncertainty of bioclimate envelope models based on the geographical distribution of species. Global Ecology and Biogeography, Oxford, v.14, p.575584, 2005.

NAVARRO C.; PARRA M. A. Plantación. $6^{\text {th }}$ ed. In: BARRANCO, D.; FERNANDEZ-ESCOBAR, R. El cultivo del olivo. Madri: Mundi-Prensa, 2008. p. $188-238$.

OLIVEIRA A. F.; PÁDUA J. G.; MATOS L. E. S. Cultura da oliveira (Olea europaea L.). Belo Horizonte: EPAMIG, 2002. 6 p. (Circular Técnica, 150).

OLIVEIRA, M.C. de; RAMOS, J.D., PIO, R.; CARDOSO, M.G. Características fenológicas e perfil de ácidos graxos em oliveiras no sul de Minas Gerais. Pesquisa Agropecuária Brasileira, Brasília, v.47, n.1, p.30-35. 2012.

PATTERSON, B.D. Contingency and determinism in mammalian biogeography: the role of history. Journal of Mammalogy, Topeka, v.80, p.345-360, 1999.

PETERSON, A.T. Predicting species geographic distributions models based on ecological niche modeling. Condor, Santa Clara, v.103, p.599-605, 2001.

RAXWORTHY, C.J.; MARTINEZ-MEYER, E.; HORNING, N. NUSSBAUM, R.A.; SCHNEIDER, G.E.; ORTEGA-HUERTA, M.; PETERSON, A.T. Predicting distribution of known and unknown reptile species in Madagascar. Nature, London, v.426, p.837-841, 2003. 
ROMERO, M.A.; GUTIÉRREZ, J.M.A. Un cultivo ecologico del olivo. Las Gabias: Adhera, S.L. 2002, $143 \mathrm{p}$.

SANTOS, J.F. El contexto de la olivicultura, la producción y el consumo de aceite da oliva en el mundo. Tesis Doutoral, 2002. p. 295-319.
WREGE, M. S. ; STEINMETZ, S..; GARRASTAZU, M. C.; REISSER JÚNIOR, C.; ALMEIDA, I. R. de ; HERTER, F. G.; CARAMORI, P. H.; RADIN, B. ; MATZENAUER, R.; BRAGA, H. J.; PRESTES, S. D. ; CUNHA, G. R. da; MALUF, J. R. T.; PANDOLFO, C. Atlas climático da região sul do Brasil: estados do Paraná, Santa Catarina e Rio Grande do Sul. Pelotas: Embrapa Clima Temperado, 2011. v.1, 332 p.

TAPIA et al. Manual del cultivo del olivo. La Cerena. INIA, 2003. 128 p. (INIA, Boletin, 101).

WREGE, M. S.; COUTINHO, E. F.; STEINMETZ, S.; REISSER JUNIOR, C.; ALMEIDA, I. R. de ; MATZENAUER, R. ; RADIN, B. Zoneamento agroclimático para oliveira no Estado do Rio Grande do Sul. Pelotas: Embrapa Clima Temperado, 2009. (Documentos). 